$12-2019$

\title{
Hypertension as a reason for cancellation of elective surgical cases on day of surgery: A five year audit report from the Aga khan university hospital Karachi
}

Abdul Monem

Aga Khan University, abdul.monem@aku.edu

Amjad Nadeem

Aga Khan University

Fauzia Khan

Aga Khan University, fauzia.khan@aku.edu

Follow this and additional works at: https://ecommons.aku.edu/pakistan_fhs_mc_anaesth

Part of the Anesthesiology Commons

\section{Recommended Citation}

Monem, A., Nadeem, A., Khan, F. (2019). Hypertension as a reason for cancellation of elective surgical cases on day of surgery: A five year audit report from the Aga khan university hospital Karachi. JPMA. The Journal of the Pakistan Medical Association, 69(12), 1860-1863.

Available at: https://ecommons.aku.edu/pakistan_fhs_mc_anaesth/383 


\title{
Hypertension as a reason for cancellation of elective surgical cases on day of surgery: A five year audit report from The Aga Khan University Hospital Karachi
}

Abdul Monem, Amjad Nadeem, Fauzia Anis Khan

\begin{abstract}
Objective: To assess the controllable factors in preventing undue cancellation of elective surgical cases and to suggest measures to address the issue.

Methods: The retrospective audit was conducted at the Aga Khan University Hospital, Karachi, and comprised all cancellations of elective surgery from 2011 to 2015. The cases reviewed had been cancelled primarily due to hypertension. A three-member committee regularly reviewed files regarding case cancellations and data was gathered.

Results: Of the 42,242 surgical cases scheduled during the period, $2903(6.8 \%)$ were cancelled. In $11(0.37 \%)$ of these cases, hypertension was the primary reason. Of them, 10(91\%) were men and $1(9 \%)$ woman. Overall age range was 30-77 years. Among the cancelled cases, 3(27.3\%) each belonged to neurosurgery and general surgery, 2(18\%) each to orthopaedic and urology, and 1(9\%) to ear, nose and throat surgery.

Conclusion: Hypertension as the primary reason for cancellation was low. Further reductions in these cancellations can be done by emphasis on following guidelines and their dissemination through continuing medical education. Keywords: Hypertension, Cancellation, Surgical cases. (JPMA 69: 1860; 2019) DOI:10.5455/JPMA.282318
\end{abstract}

\section{Introduction}

Cancellation of elective surgical cases after hospital admission causes emotional distress for patients and their families and resource wastage for hospital.

Uncontrolled hypertension is a common reason for such cancellations. Cancellation rates have been reported as $3.5 \%,{ }^{1} 13.4 \%^{2}$ and $39.8 \%{ }^{3}$ in different studies.

The World Hypertension Society / International Society of Hypertension (WHO/ISH) reported the incidence of hypertension as $60 \%$ in adults 4 which increases with age. ${ }^{5}$ Jaffer et al 6 reported an incidence of $25 \%$ in Pakistani population. A prevalence study from South Asian Association for Regional Cooperation (SAARC) reported a $13 \%$ to $48 \%$ incidence of hypertension. ${ }^{7}$ A survey of South Asian immigrant workers in the United Arab Emirates from Pakistan, India and Bangladesh revealed an overall incidence of $30.4 \%, 8$ and $76 \%$ of them were unaware of the disease.

The current study was planned to identify cases where hypertension was mentioned as the primary reason for the cancellation of surgery, and to see how such cancellations can be reduced.

\section{Material and Method}

The retrospective audit was conducted at the Aga Khan

Department of Anaesthesiology, Aga Khan University, Karachi, Pakistan. Correspondence: Abdul Monem. Email: abdul.monem@aku.edu
University Hospital (AKUH), Karachi, and comprised all cancellations of elective surgery from 2011 to 2015. The cases reviewed had been cancelled primarily due to hypertension. An exemption was obtained from the institutional ethical review committee for collecting data. As per the standard operating procedure (SOP) at $A K U H$, if any elective surgical case is cancelled, patient data and the reason for cancellation are entered on a designated form. All such cases are reviewed monthly by a 3-member standing committee of consultant anaesthesiologists not connected with these cases who then classify them as justified or unjustified. A record of all cancellations is kept by the departmental Quality Improvement Committee.

All the relevant data related to the five-year period was reviewed. Cardiothoracic cases were excluded. Variables noted were gender, age, type of surgery, location of preoperative assessment, same-day admission, history of hypertension, antihypertensive drugs being taken and compliance to medication, advice for consults, optimisation, level of blood pressure at the time of cancellation and whether cancellation was justified or unjustified along with the reason. The numbers of scheduled cases were collected from the operating room management system.

\section{Results}

Of the 42,242 surgical cases scheduled during the period, 2903 (6.8\%) were cancelled. Cancellation by 
Table: Detail of patients who were cancelled on the elective lists due to uncontrolled hypertension.

\begin{tabular}{|c|c|c|c|c|c|c|c|c|c|c|c|c|c|}
\hline S. No. & Age & Gender & $\begin{array}{l}\text { Pre-op ASA } \\
\text { Status }\end{array}$ & Surgery & $\begin{array}{c}\text { Listed } \\
\text { Co-morbidity }\end{array}$ & Medication & $\begin{array}{c}\text { Seen in } \\
\text { Pre-op clinic }\end{array}$ & $\begin{array}{l}\text { In pre-op } \\
\text { clinic }\end{array}$ & $\begin{array}{l}\text { On surgical } \\
\text { ward }\end{array}$ & $\begin{array}{l}\text { Recorded B.P } \\
\text { Pre-induction } \\
\text { area }\end{array}$ & $\begin{array}{l}\text { Operating } \\
\text { room }\end{array}$ & $\begin{array}{l}\text { Cancellation } \\
\text { justified/ } \\
\text { unjustified }\end{array}$ & $\begin{array}{c}\text { Case Cancelled by } \\
\text { Anaesthetist (A) } \\
\text { / Surgeon (S) }\end{array}$ \\
\hline 1 & 74 & Male & 3 & $\begin{array}{c}\text { Laparoscopic } \\
\text { Cholecystectomy }\end{array}$ & $\begin{array}{c}\text { CAD } \\
\text { Hypertension } \\
\text { (controlled) } \\
\text { - Diabetes }\end{array}$ & Yes & - & - & $148 / 69$ & $210 / 110$ & $244 / 123$ & Justified & A and $S$ \\
\hline 2 & 56 & Female & 3 & L3 Microdiscectomy & $\begin{array}{l}\text { Hypertension } \\
\text { (controlled) }\end{array}$ & Tenormin & - & - & $157 / 96$ & $145 / 95$ & $\begin{array}{c}165 / 110 \\
\text { HR 136-140 } \\
\text { ST changes }\end{array}$ & Justified & A and $S$ \\
\hline 3 & 50 & Male & 2 & $\begin{array}{l}\text { Intramedullary } \\
\text { nailing of femur }\end{array}$ & $\begin{array}{l}\text { Hypertension } \\
\text { (controlled) } \\
\text { - Diabetes }\end{array}$ & Lozar & - & - & $160 / 100$ & $170 / 120$ & - & Justified & $S$ \\
\hline 4 & 77 & Male & 2 & $\begin{array}{l}\text { Laparoscopic } \\
\text { Cholecystectomy }\end{array}$ & $\begin{array}{l}\text { Hypertension } \\
\text { (controlled) }\end{array}$ & $\begin{array}{l}\text { Amlodipine } \\
\text { Metoprolol }\end{array}$ & Yes & $130 / 62$ & $164 / 67$ & - & - & Unjustified & S \\
\hline 5 & 36 & Male & 1 & $\begin{array}{l}\text { Ureterorenoscopy } \\
\text { and DJS insertion }\end{array}$ & - & - & - & - & - & 199/97 & - & Unjustified & $S$ \\
\hline 6 & 30 & Male & 2 & $\begin{array}{l}\text { Repair of } \\
\text { Radial nerve }\end{array}$ & - & - & Yes & $140 / 80$ & $136 / 93$ & - & - & Unjustified & S \\
\hline 7 & 30 & Male & 3 & $\begin{array}{l}\text { Retroperitoneal } \\
\text { mass excision }\end{array}$ & Hypertension & No treatment & Yes & $\begin{array}{l}\text { 162/124 } \\
\text { HR } 111\end{array}$ & - & - & - & Unjustified & S \\
\hline 8 & 65 & Male & 2 & Laminectomy & Hypertension & Perindopril & Yes & $154 / 105$ & 168/117 & 210/134 & - & Unjustified & A \\
\hline 9 & 45 & Male & 2 & PCNL & Hypertension & Norvasc & Yes & $180 / 120$ & $161 / 112$ & - & - & Unjustified & A \\
\hline 10 & 50 & Male & 2 & $\begin{array}{c}\text { Spinal instrumentation } \\
\text { D5 - D9 }\end{array}$ & Anaemia & - & Yes & - & $156 / 110$ & - & - & Unjustified & $S$ \\
\hline 11 & 57 & Male & 2 & $\begin{array}{l}\text { Submandibular lymph } \\
\text { nodes excision } \\
\text { (Day Care) }\end{array}$ & $\begin{array}{c}\text { CAD } \\
\text { Hypertension } \\
\text { (controlled) } \\
\text { Diabetes }\end{array}$ & On Medication & Yes & \multicolumn{2}{|c|}{ 138/85 190/110 chest heaviness } & - & - & Unjustified & A \\
\hline
\end{tabular}

CAD: Coronary artery disease; PCNL: Percutaneous nephrolithotomy; NA: not available; HR: Heart rate.

anaesthesiologists were $87(3 \%)$. In $11(0.37 \%)$ of the total cancelled cases, hypertension was the primary reason. Of them, 10(91\%) were men and $1(9 \%)$ woman. Overall age range was $30-77$ years, and $3(27.3 \%)$ cases were below 40 years of age.

Among the cancelled cases, $3(27.3 \%)$ each belonged to neurosurgery and general surgery, 2(18\%) each to orthopaedic and urology, and $1(9 \%)$ to ear, nose and throat surgery.

Besides, 7(64\%) cases had undergone preoperative assessment at the clinic and $4(36 \%)$ had been assessed in the ward. Only $1(9 \%)$ case was day-care admission. Also,
$8(73 \%)$ cases were known hypertensives, while in the remaining $3(27 \%)$, hypertension was discovered on the day of the admission.

Three (27\%) patients had a preoperative blood pressure reading of less than $180 / 110 \mathrm{mmHg}$. Overall, $3(27 \%)$ cancellations were labelled justified (Table).

\section{Discussion}

The audit revealed that $0.37 \%(n=11)$ of the total booked cases on elective surgical lists were cancelled due to hypertension, and $73 \%$ of these were known hypertensives. The figure accounted for $12.6 \%$ of total 
anaesthesia cancellations.

An audit across National Health Service (NHS) hospitals in the United Kingdom revealed that uncontrolled hypertension accounted for 0.5 to $1.5 \%$ of the total booked cases. ${ }^{9}$ Mesmar et al ${ }^{10}$ reported $11 \%$ cancellation of scheduled cases due to uncontrolled hypertension. This is similar to our result of $12.6 \%$. A one-year retrospective survey of 25 hospitals in Saudi Arabia 11 documented $7.6 \%$ case cancellation rate, with $4.12 \%$ due to hypertension. A study 3 from Sudan reported a higher figure of $39.8 \%$ of cancellations due to hypertension.

Studies from Pakistan haven't specifically looked at hypertension as the sole reason for cancellation. Hussain etal. ${ }^{1}$ reported 28 cancellations by the anaesthetist over a period of one year in a tertiary care hospital. In this audit, only one patient was cancelled due to higher blood pressure (BP) $>180 / 110 \mathrm{mmHg}$, (0.01\% of all cancelled cases and $3.5 \%$ of all anaesthetic cancellations). In another local study, uncontrolled BP and cardiac problems accounted for $15.08 \%$ of cancellations. ${ }^{12}$ A study from Tanzania ${ }^{13}$ reported $17.5 \%$ cancellation due to uncontrolled medical conditions, hypertension being one of them.

Current guidelines from the Association of Anaesthetists of Great Britain and Ireland (AAGBI), and British Hypertension Society (BHS) ${ }^{9}$ recommend moving ahead with surgery if preoperative BP is less than 180/110 $\mathrm{mmHg}$. A higher pressure may warrant intervention, particularly in patients with known risk factors like coronary artery disease (CAD). The aim should be to decrease the blood pressure slowly over 30-60 minutes and by no more than $25 \%$ to a target value less than $180 / 110 \mathrm{mmHg}$. James et al. ${ }^{14}$ recommended investigating for target organ damage in previously undiagnosed hypertensive patients prior to surgery. They strongly denounced cosmetic correction of high BP just prior to surgery. Three of our patients were cancelled with $\mathrm{BP}<180 / 110 \mathrm{mmHg}$.

The importance of audits of unjustified cancellation is to identify any correctable factors and to prevent them. Such data can be used to bring about system changes in patient management. Preoperative assessment is indicated prior to surgery to optimise any comorbidity. ${ }^{9}$ The patient should be again evaluated prior to surgery as the physical condition might change over the course of time since the first assessment. In case of a decision to cancel, the anaesthesiologist and surgeons should mutually discuss and agree. If such discussion had taken place, some of the cases that were cancelled by the surgeons would have been acceptable for anaesthesia in our study based on current guidelines.
In lower and middle income countries (LMICs), patients often present to the specialist for the first time as there is no existing screening system in the health services. Hence, the chance of discovering hypertension at the time of hospital admission increases. Our rate of cancellation due to hypertension was not different to that reported from the UK, but this may be because majority of our patients were screened in the preoperative clinic. In hospitals where these clinics do not exist, the cancellation rate may be higher.

Dissemination of guidelines and their implementation may also help to reduce the burden of unjustified cancellations. This can be achieved through continuing medical education (CME) activities and sharing of guidelines in multidisciplinary meetings.

The current audit has some limitations as it was a retrospective audit, and inadequate documentation accounted for some missing information. Compliance with antihypertensive medication was also not adequately documented.

\section{Conclusion}

The five-year audit revealed that hypertension as the primary reason for cancellation was only $0.37 \%$ of the total cancellations and $12.6 \%$ of total anaesthesia-based cancellations. It is low in comparison to other studies in the region and is comparable with developed countries. However, similar audits are recommended to be conducted in other Pakistani institutions to assess the rate of unjustified cancellations and to improve systems.

\section{Disclaimer: None.}

\section{Conflict of Interest: None.}

\section{Source of Funding: None.}

\section{References}

1. Hussain AM, Khan FA. Anaesthetic reasons for cancellation of elective surgical inpatients on the day of surgery in a teaching hospital. J Pak Med Assoc. 2005; 55:374-8.

2. Lau HK, Chen TH, Liou CM, Chou MC, Hung WT. Retrospective analysis of surgery postponed or cancelled in the operating room Taiwan. J Clin Anesth. 2010; 22: 237-40.

3. Elrehman AA, Hamza AA, El-Haj MA. Cancellation of Elective General Surgical Operations at the Day of Intended Surgery. Global J Med Res. 2014; 14: 38-44.

4. Howell SJ, Sear JW, Foëx P. Hypertension, hypertensive heart disease and perioperative cardiac risk. Br J Anaesth. 2004; 92: 570 83.

5. Rao CR, Kamath VG, Shetty A, Kamath A. High Blood Pressure Prevalence and Significant Correlates: A Quantitative Analysis from Coastal Karnataka, India. ISRN Prev Med. 2012; 2013: 574973.

6. Jafar TH, Levey AS, Jafary FH, White F, Gul A, Rahbar MH, et.al. Ethnic subgroup differences in hypertension in Pakistan. J Hypertens. 2003; 21: 905-12. 
7. Neupane D, McLachlan CS, Sharma R, Gyawali B, Khanal V, Mishra $\mathrm{SR}$, et.al. Prevalence of Hypertension in Member Countries of South Asian Association for Regional Cooperation (SAARC): systematic review and meta-analysis. Medicine (Baltimore). 2014; 93: e74.

8. Shah SM, Loney T, Hussein MS, Sadig ME, Dhaheri SA, Barazi IE, et al. Hypertension prevalence, awareness, treatment, and control, in male South Asian immigrants in the United Arab Emirates: a cross-sectional study. BMC Cardiovasc Disord. 2015; 15: 30.

9. Hartle A, McCormack T, Carlisle J, Anderson S, Pichel A, Beckett N, et.al. The measurement of adult blood pressure and management of hypertension before elective surgery. Joint Guidelines from the Association of Anaesthetists of Great Britain and Ireland and the British Hypertension Society. Anaesthesia. 2016; 71:326-37.

10. Mesmar M, Shatnawi NJ, Faori I, Khader YS. Reasons for cancellation of elective operations at a major teaching referral hospital in Jordan. East Mediterr Health J. 2011; 17:651-5.

11. Dhafar KO, Ulmalki MA, Felemban MA, Mahfouz ME, Baljoon MJ Gazzaz ZJ, et.al. Cancellation of operations in Saudi Arabian hospitals: Frequency, reasons and suggestions for improvements. Pak J Med Sci. 2015; 31:1027-32.

12. Afzal F, Asad N, Ali K. Causes of postponement of elective surgery in Mayo Hospital Lahore. Biomedica. 2010; 26: 148-51.

13. Chalya PL, Gilyoma JM, Mabula JB, Simbila S, Ngayomela IH, Chandika $A B$, et.al. Incidence, causes and pattern of cancellation of Elective surgical operations in a University Teaching Hospital, Tanzania. Afr Health Sci. 2011; 11: 438-43.

14. James MFM, Dyer RA, Rayner BL. A modern look at hypertension and anaesthesia. JEMDSA. 2014; 19: 56-61. 